\title{
SOLETR \\ R E \\ Sob o domínio do Rei Peste: a função das doenças e epidemias no Gótico brasileiro da República Velha
}

\author{
Alexander Meireles da Silva ${ }^{1}$ \\ Universidade Federal de Goiás
}

\begin{abstract}
Resumo: Ainda que tenha testemunhado intensos conflitos nacionais como a Revolta de Canudos, a Guerra do Contestado, a Revolta da Vacina e a Revolta da Chibata, a República Velha (1889-1930) teve nas pestes e epidemias os inimigos mais ferozes a serem combatidos para o desenvolvimento do país. Com base nesta afirmação e tomando como suporte teórico o conceito do monstruoso de Noël Carroll e Jeffrey Jerome Cohen assim como também as ideias de H. P. Lovecraft e Edmund Burke sobre a função do medo na literatura fantástica, este artigo tem como meta demonstrar como a sífilis, a febre amarela, a varíola, a peste bubônica e a hanseníase exerceram significativa influencia na manifestação de narrativas no meio literário brasileiro cujas estruturas e temáticas guardam semelhanças com a literatura gótica do século dezenove praticada na Inglaterra e nos Estados Unidos. Dentre outros contos de autores como Valdomiro Silveira, Hugo de Carvalho Ramos e Monteiro Lobato, a análise de "O bebê de tarlatana rosa" e "A peste", ambos de João do Rio e "O mosquito" e "Niobe", escritos por Coelho Neto demonstra que as pestes e epidemias foram utilizados pelos escritores nacionais para veicular a visão ideológica das elites sobre grupos sociais e regiões geográficas dentro do discurso modernizante vigente no país da época.
\end{abstract}

Palavras-chave: República Velha. Gótico brasileiro. Epidemia.

Este artigo tem como meta demonstrar como as doenças e epidemias que assolaram o Brasil durante o período histórico conhecido como República Velha (1889 - 1930) tiveram significativa influência na manifestação de narrativas no meio literário brasileiro cujas estruturas e temáticas guardam semelhanças com a literatura gótica anglo-americana do século dezenove. A análise mostra que doenças contagiosas no Brasil da virada do século dezenove para o século vinte como, dentre outras, a sífilis, a febre amarela, a varíola, a peste bubônica e a hanseníase, foram utilizadas por escritores nacionais diversos para veicular a ideologia das elites sobre grupos sociais e regiões geográficas dentro do discurso modernizante vigente no país da época. No entanto, a tensão entre classes sociais tendo o

\footnotetext{
${ }^{1}$ Doutor em Literatura Comparada pela Universidade Federal do Rio de Janeiro (2008) e Mestre em Literaturas de Língua Inglesa pela Universidade Estadual do Rio de Janeiro (2003). Desde 2009, atua como Professor Adjunto de Língua Inglesa e Literaturas Correspondentes do Departamento de Letras da Universidade Federal de Goiás - Campus Catalão, onde também exerce a função de Coordenador do Centro de Línguas do CAC / UFG. Professor permanente do Mestrado em Estudos da Linguagem do CAC / UFG. É líder do Grupo de Pesquisa L.I.M.E.S. (Literatura, Imaginário, Marginalidade, Estética e Sociedade). É autor do livro Literatura Inglesa para brasileiros: curso completo de literatura e cultura inglesa para brasileiros (2005), pela editora Ciência Moderna. Suas pesquisas se concentram nas áreas das Literaturas de Língua Inglesa e da Literatura Fantástica. 
$\begin{array}{llllllll}\text { R } & \text { E } & \text { V } & \text { I } & \text { S } & \text { T } & \text { A Dossiê - N. 27-2014.1-Alexander Meireles da Silva }\end{array}$

racionalismo como base pode ser observada desde a ascensão do pensamento científico na Europa renascentista.

Os desdobramentos do Renascimento que varreu a Europa nos fins do século quatorze até o início do século dezessete mudaram a concepção do homem com relação ao seu papel perante o mundo. $\mathrm{O}$ emergente pensamento científico adquire um papel de observador dos eventos mundanos, descrevendo fatos, analisando informações e propondo ideias que progressivamente passaram tanto a contrariar as crenças estabelecidas das camadas populares na Europa quanto a questionar as verdades religiosas absolutas. Esse começo de distanciamento entre o pensamento racionalista de um lado e o religioso e popular do outro se intensificou no século dezessete. Como atesta Keith Thomas, "por volta de meados do século XVII, os novos desdobramentos intelectuais haviam ampliado enormemente a brecha que havia entre as classes cultas e os extratos inferiores da população rural" (THOMAS, 1971, p. 536). As descobertas científicas criaram terreno para a vitória da razão e da ciência sobre os domínios da Igreja. Dentre tantas invenções e descobertas do período, foram os estudos a respeito da constituição do ser humano que trouxeram o maior impacto sobre o entendimento do homem sobre si mesmo, retirando-o da esfera da religião e levando-o ao terreno da razão. William Harvey, por exemplo, publica em 1628 seu estudo sobre a circulação do sangue no corpo humano. A ascensão dos métodos experimentais, preconizados por pensadores como Francis Bacon, René Descartes, e o próprio Harvey, levou à criação de grupos que se reuniam para debater as novidades da ciência. Dessas reuniões, nasceriam a Sociedade Real de Londres em 1662 e a Academia Real de Ciências de Paris em 1666, instituições divulgadoras do saber científico cuja existência permitiu que em 1673 a humanidade viesse a conhecer uma das maiores invenções da história: o microscópio (UJVARI, 2003, p. 127), que permitiu avanços em várias áreas da ciência. O progresso da ciência foi tão grande no decorrer do século dezessete que houve a necessidade de se reunir os conhecimentos filosóficos e científicos de então numa publicação única que demonstraria ao povo o poder da razão sobre a religião e que confirmaria o orgulho da burguesia: A Enciclopédia, de Denis Diderot e Jean d'Alembert (THOMAS, 1971, p. 525-526).

No século seguinte, apesar dos (ou devido aos) esforços dos iluministas do século dezoito, a hegemonia do racionalismo foi alvo das críticas por parte de obras que questionavam o caráter redentor atribuído à ciência. Dentre elas, uma se destaca por ser a primeira obra especulativa ficcional questionadora do papel da ciência: As viagens de Gulliver (1726), do Irlandês Jonathan Swift. A obra de Swift aborda as principais questões filosóficas, 
R E V I $\quad$ S $\quad$ T $\quad$ A Dossiê - N. 27-2014.1-Alexander Meireles da Silva políticas e científicas de seu tempo. Nas duas primeiras viagens de Gulliver, por exemplo, ele entra em contato com os minúsculos habitantes da ilha de Liliput, e a seguir com o gigantesco povo da ilha de Broddingnag. Tanto na primeira quanto na segunda viagem, a proporção dos povos narrados serve para indicar que Liliput e Broddingnag são o nosso próprio mundo, só que vistos pelos novos instrumentos científicos da época: o microscópio e o telescópio respectivamente (AMIS, 1960, p. 24-25). Se na quarta e última viagem Gulliver consolida seu desprezo pela humanidade após se deparar com os houyhnhnms, uma raça de cavalos inteligentes e os selvagens humanos yahoos, sua terceira viagem tem importância especial para a crítica à ciência: Gulliver entra em contato com a ilha flutuante de Laputa, uma ilha mantida suspensa do chão por magnetismo e que é habitada por matemáticos teóricos perdidos em seus cálculos abstratos e alienados do mundo ao seu redor, mostrando como Swift caçoa do conhecimento que não traz benefício prático para a humanidade. $\mathrm{O}$ acúmulo de informações, no entanto, não deixaria que a ciência se mantivesse por muito mais tempo na posição de expectadora dos eventos, distante da realidade como os cientistas de Laputa. Se, como Bacon pregava, "conhecimento é poder", então era o momento de se interferir ativamente para que as leis da Natureza atuassem no sentido de aprimorar a vida das pessoas reagindo, assim, à crítica de Swift. A oportunidade veio enfim no final do século dezoito, quando a vacina antivariólica foi criada.

Difundindo-se indiscriminada e violentamente, até a sua plena erradicação, a varíola, conforme observa Tânia Maria Fernandes (1999, p. 11), “dizimou populações ao longo dos séculos, deixando marcas físicas e sociais indeléveis". Nos séculos dezessete e dezoito, por exemplo, a despeito dos conhecimentos científicos da época, um terço dos habitantes de Londres apresentavam cicatrizes horríveis e dois terços ficaram cegos em decorrência da doença (UJVARI, 2003, p. 130). Ainda que há séculos os chineses já inoculassem seus doentes com o material proveniente das lesões, somente no princípio do século dezoito tal conhecimento chegou aos ouvidos da Sociedade Real. O método em si era objeto de discussão, tanto por parte dos membros da instituição, visto os riscos de transmissão de outras doenças e até de morte, quanto por parte da Igreja, que pregava a natureza divina da varíola como um instrumento de Deus. Enquanto os debates continuavam, o médico Edward Jenner visitava sua terra natal e ficou intrigado com o fato de que as mulheres que trabalhavam com a ordenha das vacas em seu condado não contraíam a varíola. Em 14 de maio de 1796 ele resolveu inocular no pequeno doente James Phipps o conteúdo das pústulas da cowpox, uma doença bovina que era transmitida para as mãos das ordenhadoras. Diante do sucesso 


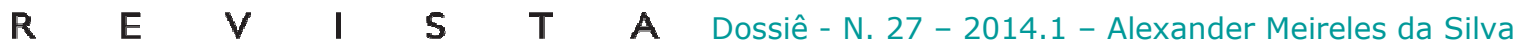

alcançado, ele repetiu a experiência em outras pessoas, incluindo seus filhos. Apesar dos resultados positivos, seu trabalho foi rejeitado pela Sociedade Real devido ao baixo número de casos relatados. Essa rejeição levou Jenner a publicar em 1798 um livro sobre a inoculação do cowpox para a proteção contra a varíola. Por ter usado o termo latino referente à vaca em sua obra, vacina, sua técnica ganhou reconhecimento, tornando-se um recurso que protegia a população contra a varíola, o que deu origem a essa denominação usada até hoje. Vale a pena citar neste ponto o comentário de Jeanette Farrell sobre a repercussão da ação de Jenner:

Jenner passou de médico do interior para salvador do mundo. A imperatriz da Rússia enviou-lhe um anel de diamante. Em Berlim, as pessoas começaram a comemorar o 14 de maio como o dia da vacinação de James Phipps. Na época de Jenner, a Grã-Bretanha e a França estavam empenhadas nas guerras napoleônicas. No entanto, Napoleão, o implacável líder francês, libertou soldados britânicos capturados quando Jenner lhe pediu que fossem perdoados (FARRELL, 2002, p. 53).

Mais do que a própria vacina, a descoberta de Jenner introduziu uma ideia revolucionária de interesse central neste projeto: pela primeira vez, os seres humanos podiam efetivamente impedir uma doença, influenciar o curso da Natureza. Como confirma Tânia Maria Fernandes, "a vacina antivariólica constitui a primeira iniciativa frutífera em direção ao controle imunitário das doenças infecciosas" (FERNANDES, 1999, p. 11). Mas, se pelo lado de reis e imperadores a vacina era louvada pelo seu caráter divino, pelo lado do povo ela representava o símbolo mais evidente da interferência do homem sobre os planos de Deus. A ciência e seus homens passam definitivamente a ser o objeto tanto de admiração quanto de desconfiança por parte das camadas populares na Europa e, por conseguinte, no Brasil do Império.

Apesar de seus inegáveis resultados positivos, a vacinação foi alvo de críticas que podem ser restritas a dois temas que por vezes se inter-relacionavam: o primeiro, preconizado pela Igreja, argumentava que deter a varíola era colocar-se contra a vontade de Deus, visto que a varíola era tida como um castigo divino (UJVARI, 2003, p. 133). A segunda argumentação contra a vacina, que alcançou expressão até mesmo entre alguns meios científicos, era a de que, ao se introduzir um produto terapêutico extraído da vaca, as pessoas desenvolveriam características físicas do animal, além da possibilidade de transmitir doenças até então restritas aos animais para os inoculados (FERNANDES, 1999, p. 21). Em decorrência dessa resistência, os governos passaram a tentar aprovar leis que forçavam as pessoas a se vacinar, o que gerou um prolongado, acirrado, e até mesmo violento debate sobre 
$\begin{array}{llllllll}\text { R } & \text { E } & \text { V } & \text { I } & \text { S } & \text { T } & \text { A } & \text { Dossiê - N. 27-2014.1-Alexander Meireles da Silva }\end{array}$

a liberdade de escolha e o papel da ciência sobre a vida das pessoas envolvendo intelectuais, cientistas, políticos, religiosos e, por fim, o povo (FARRELL, 2002, p. 56).

No Brasil, este quadro de embate entre o racionalismo e os costumes e crenças encontrou seu ambiente ideal para florescimento no começo do século vinte, quando as medidas adotadas pelas instituições de poder da República Velha fomentaram a revolta popular que ficou conhecida como A Revolta da Vacina:

O quebra-quebra dominou o centro da cidade e o governo perdeu o controle da situação. Arandelas de gás partidas, postes de iluminação vergados, fragmentos de vidro por toda a parte, paralelepípedos arrancados, bondes virados e incendiados, 700 presos, 65 feridos e 20 mortos - esse foi o saldo do protesto, conhecido como a Revolta da Vacina (ZANCHETTA, 1988, p. $53)$.

A descrição de Maria Inês Zanchetta sobre o tumulto que convulsionou a sociedade carioca em 1904 dá a dimensão exata do grau de descontentamento de parte da sociedade brasileira pelas ações do governo Federal e da reação deste governo contra os chamados “criminosos". A rebelião carioca contra a ordem institucional foi objeto de preocupação pelo governo Federal por acontecer dentro de seus domínios diretos, a então capital da República, o Rio de Janeiro. Tal proximidade levou o governo a agir duramente contra os considerados envolvidos na agitação, o que serviu apenas para marcar ainda mais a Revolta da Vacina como um dos episódios mais significativos para se compreender a evolução de alguns dos problemas do meio urbano brasileiro. Exemplo disso é a presença das favelas no cenário carioca como derivada, em parte, das ações governamentais perpetradas ainda no governo do presidente Rodrigues Alves (1902-1906). Essa revolta explodiu nas ruas do Rio de Janeiro, no período de 12 a 15 de novembro de 1904 e se caracterizou por uma mobilização da camada mais pobre da população descontente com as seguidas medidas adotadas pelo governo de Rodrigues Alves. Dentre as medidas impopulares de impacto mais profundo sobre a vida da população, duas ocuparam lugar de destaque como causas imediatas da revolta: o projeto de reforma e modernização da capital federal perpetrado pelo prefeito Francisco Pereira Passos e as ações sanitaristas adotadas pelo médico Oswaldo Cruz.

Antes mesmo de tomar posse da presidência da República, em 1902, Rodrigues Alves anunciou: "O meu programa de governo vai ser muito simples. Vou limitar-me a duas coisas: o saneamento e o melhoramento do porto do Rio de Janeiro" (SAGA, 1981, p. 150). De fato, ao chegar ao poder, o novo presidente tratou de aplicar seu programa de governo que, se na teoria era simples, se provou muito problemático na prática. Para o projeto de modernização do centro da cidade, Rodrigues Alves designou o engenheiro Pereira Passos. Já prevendo a 


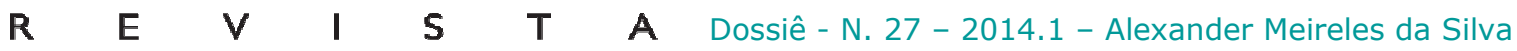

envergadura da obra, assim como também as reações contra ela, principalmente por parte do povo, Passos exigiu do presidente poderes plenos sem direito a contestações. Nomeado prefeito do Distrito Federal, Passos conseguiu seus poderes através de uma alteração de lei perpetrada pelo presidente, que se configurou, na análise de figuras de proa da época, como o jurista Afonso Arinos de Melo e o político Rui Barbosa, contemporâneos de Pereira Passos, como uma lei, "equívoca, arbitrária e visivelmente anticonstitucional, atribuindo poderes tirânicos ao prefeito e retirando qualquer direito de defesa à comunidade" (SEVCENKO, 1984, p. 35). Amparado pela lei, o prefeito começou a colocar em prática as medidas que visavam transformar a capital Federal em uma cidade moderna, organizada, ampla, enfim, inserida no século vinte. Tais medidas se caracterizavam por demolir casas, casebres, prédios e cortiços que impedissem a ampliação e modernização da cidade e consequentemente foram retirados os habitantes de tais locações, sem direito a indenizações ou avisos prévios. Logo, o povo começou a tratar as atividades da prefeitura como a "Ditadura Passos" (SEVCENKO, 1984, p. 36). Nasce aí um relacionamento entre espaços sociais que ficou caracterizado não apenas pela gradual e inexorável favelização da paisagem carioca em um jogo especular com a modernização da cidade, mas também pela desconfiança da população pobre em relação às instituições mantenedoras do status quo, postura esta representada com maestria por Aluisio Azevedo em $O$ cortiço (1890):

A polícia era o grande terror daquela gente, porque, sempre que penetrava em qualquer estalagem, havia grande estrupício: à capa de evitar e punir o jogo e a bebedeira, os urbanos invadiam os quartos, quebravam o que lá estava, punham tudo em polvorosa. Era uma questão de ódio velho (AZEVEDO, 1997, p. 99).

Se o governo já havia gerado enorme descontentamento em sua busca por modernizar a cidade, ele acabou por fornecer o ingrediente final para a explosão popular com a decisão de erradicar a Capital Federal das frequentes epidemias que traziam má reputação para os portos cariocas (UJVARI, 2003, p. 232). Para esse papel, surge a figura de Oswaldo Cruz.

Nomeado por Rodrigues Alves através da indicação de seu ministro do Interior J. J. Seabra, Oswaldo Cruz demonstrou uma tenacidade sem paralelo para dar cabo das doenças que costumeiramente assolavam a população carioca. Assim como Pereira Passos, Cruz exigiu do presidente carta branca para tocar seus projetos de desinfecção e profilaxia da capital. Já empossado como Diretor Geral da Saúde Pública, Oswaldo Cruz se empenhou no combate à febre amarela, à peste bubônica e à varíola. Quanto a esta última, se destaca o empenho do médico em centralizar sob seu controle a fabricação da vacina antivariólica. É, aliás, o cumprimento da lei de obrigatoriedade da vacinação contra a varíola, requisitada e 
$\begin{array}{llllllll}\text { R } & \text { E } & \text { V } & \text { I } & \text { S } & \text { T } & \text { A } & \text { Dossiê - N. 27-2014.1-Alexander Meireles da Silva }\end{array}$

defendida ardentemente por Oswaldo Cruz, que detona a rebelião popular. Receosos com os boatos de que a vacina feita com a própria doença poderia transmitir sífilis e até doenças de animais, a população pobre se rebela. Se a "Ditadura Passos" lhes havia tirado a moradia, a "Ditadura Sanitária" (SEVCENKO, 1984, p. 38), como popularmente foram chamadas as ações dos agentes sanitários de Cruz, não haveria de lhes tirar o controle de seu próprio corpo. Foi o estopim para a Revolta da Vacina.

Neste ponto, é importante esclarecer que, mais do que as medidas realizadas pelo governo em si, a maneira como estas foram implantadas determinaram a revolta da população. Ainda que principalmente as medidas de Oswaldo Cruz tenham visado à redução das seguidas epidemias que assolavam o território do Rio de Janeiro, a falta de esclarecimento por parte da população e a truculência dos agentes do governo encarregados de executarem as ações criaram uma onda crescente de insatisfação que denunciava o total desprezo da elite pensante do país pelas chamadas "massas", vinculadas pela ideologia dominante às epidemias de febre amarela, varíola, peste bubônica e lepra que precisavam ser erradicadas da idealizada "Paris tropical”. Como salienta Aquino, citado por Mittelman,

Foi com este sentido que médicos e engenheiros, principais representantes da ciência no Brasil àquela altura, considerando-se os principais responsáveis pela salvação do povo brasileiro, articularam suas propostas de superação nacional, esboçando projetos de nação articulada ao conceito de progresso [e que] o discurso científico tornou-se um instrumento privilegiado para a legitimação de uma ordem social, não levando em conta direitos de cidadania de amplos setores da população [...] (AQUINO apud MITTELMAN, 2003, p.11-12).

A postura da elite dominante do Brasil, refletindo uma visão neocolonial ou imperialista internalizada na República Velha, evidenciou a presença do "darwinismo social”, ou seja, a tese de que a evolução e a história social são governadas pelos mesmos princípios que regulam a evolução das espécies na Natureza, de modo que conflitos entre e dentro das culturas se constituem numa luta pela existência que é o motor do progresso (CAUSO, 2003, p. 137). Aqui, é fundamental esclarecer que o próprio Charles Darwin não era um darwinista social, preferindo acentuar a cooperação entre as sociedades humanas como o fator primordial da sobrevivência.

Como era de se esperar, os escritores brasileiros não ficaram incólumes diante desses acontecimentos, que evidenciaram ainda mais não apenas o posicionamento da elite política e cultural, ansiosa pela modernização da nação, em relação a um Brasil ainda essencialmente rural e com forte herança colonial e escravocrata, mas também a própria situação de transição da literatura brasileira da época, visto que o início do século vinte foi um estertor das 
R $\quad$ E $\quad$ V $\quad$ I $\quad$ S $\quad$ T $\quad$ A Dossiê - N. 27-2014.1-Alexander Meireles da Silva correntes literárias do século dezenove e um palco de entrada para o Modernismo (BOSI, 2006, p. 197). Assim, este período literário pode ser visto como um tempo devedor do passado e antecipador do futuro. Uma vez apresentado o quadro geral, e tomando como suporte teórico o conceito do monstruoso, de Noël Carroll (1999) e Jeffrey Jerome Cohen (2000), assim como as ideias de H. P. Lovecraft e Edmund Burke sobre a função do medo na literatura fantástica, passa-se para a breve análise literária desse cenário, em que a abordagem das doenças e epidemias e a vinculação destas com grupos minoritários na sociedade brasileira do início do século vinte aproximaram as narrativas brasileiras das convenções e estratégias do Gótico inglês no que se refere as subversões de normas, desintegração mental e corrupção mental (BOTTING, 1996, p. 1), elementos que se alinham com os sintomas das principais doenças e epidemias que acometiam o Brasil: Sífilis, varíola, febre amarela e lepra.

Escrito sob a influência de Krafft-Ebing e de sua Psychopathia Sexualis (1886), o principal manual do discurso médico e positivista do século dezenove sobre as diferentes formas de perturbação da vida sexual humana, "o bebê de tarlatana rosa" (1910), de João do Rio, traz a mortal sífilis como um dos constituintes da sua atmosfera sobrenatural, estabelecendo um dialogo direto com a "A máscara rubra da morte" (1842), de Edgar Allan Poe. É interessante comentar de fato que, a despeito de ter sido a mais agressiva doença venérea do século dezenove, levando a morte vários escritores do período, a sífilis foi apenas abordada de forma indireta pela literatura fantástica na Europa e no Brasil, dado o rígido código vitoriano sobre o sexo. Ainda assim, há claros elementos na representação de personagens góticos como Drácula e Dr. Jekyll / Mr. Hyde, relacionados aos sintomas da sífilis, como a decadência física e mental sentida pelos doentes. O mesmo também se encontra na personagem do bebê de tarlatana rosa depois que esta é desmascarada pelo pervertido Heitor de Alencar na última noite de Carnaval, revelando "uma cabeça sem nariz, com dois buracos sangrentos atulhados de algodão, uma caveira que era alucinadamente uma caveira com carne...” (RIO, 1981, p. 60). Enojado pela imagem especular de sua própria decadência e podridão moral, o narrador foge da corporificação da sífilis e da realidade escondida na noite da Belle Époque carioca, uma realidade que vincula a personagem de João do Rio ao monstro coheniano: "O monstro nasce nessas encruzilhadas metafóricas, como a corporificação de um certo momento cultural - de uma época, de um sentimento e de um lugar" (COHEN, 2000, p. 26). No caso de "o bebê de tarlatana rosa", o uso da máscara de bebê aponta para um ser de sexualidade não definida, o que permite a leitura de que o usuário do adereço é um travesti. 


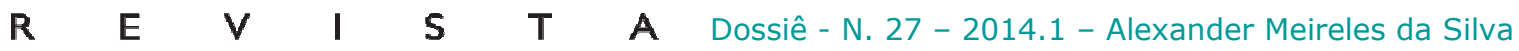

Tal interpretação é reforçada pelo fato de que a sífilis sempre foi vinculada diretamente aos homossexuais e prostitutas, criaturas desviantes (RICHARDS, 1993, p. 135).

Se a sífilis era tema de conversa proibida nos salões da Belle Époque, em decorrência dos códigos sexuais da época, o mesmo não pode ser dito da varíola, dada a situação epidêmica da doença nos principais centros urbanos brasileiros no início do século vinte, sendo associada às condições de vida insalubres das classes sociais mais baixas, associação esta que, com o tempo, fez com que a população pobre fosse vista como perigosa. Esta vinculação varíola $=$ pobreza $=$ perigo também se faz presente no conto "Os livres acampamentos da miséria" (1917), de João do Rio, no qual um narrador dândi decide acompanhar um grupo de negros seresteiros ao morro de Santo Antônio, no centro do Rio de Janeiro. Ao chegar no alto do morro, de onde vislumbra as luzes da cidade, ele lembra: "De repente, lembrei-me que a varíola cairia ali ferozmente, que talvez eu tivesse passado pela toca dos varilosos. Então, apressei o passo de todo" (RIO, 1981, p. 84). Mas foi em "A peste" (1910) que o cronista carioca abordou todo o horror provocado pela varíola e seus efeitos sobre o corpo humano, descrevendo a desestruturação social causado pela doença e evidenciando a atmosfera de podridão tão cara aos artistas decadentes em sua crítica aos valores burgueses da modernidade:

A sinistra rebentava em purulências toda a cidade. Um dia em que passava por uma igreja, Francisco ouviu os sinos a badalar sinistramente. Teve a curiosidade de saber por quem tão tristes badalavam e perguntou a um velho. - É promessa, meu senhor, é para que Santo Antônio não mate a todos nós de bexiga (RIO, 1981, p. 62-63).

A despeito de seus temores e das prevenções tomadas, no entanto, o jovem Francisco Nogueira contrai a "doença da bexiga", como a varíola também era conhecida no início do século vinte. Seu amigo, Luciano Torres, decide visitar Francisco no hospital dos varilosos e não consegue esconder o medo diante do prédio:

Eu tenho medo, oh! muito medo... E aquele trecho da secretaria não é para acalmar o destrambelhamento dos meus nervos. Tudo é branco, limpo, asseado, com o ar indiferente nas paredes, nos móveis sem uma poeira. Os empregados, porém, movem-se com a precipitação triste a que a morte obriga os que ficam. (...) há mulheres pálidas e desgrenhadas que esperam novas dos seus doentes, há velhos, há homens de face desfeita, uma série de caras em que o mistério da morte, lá fora, entre as árvores, incute um apavorado respeito e uma sinistra revolta (RIO, 1981, p. 64).

As palavras de Luciano Torres trazem à mente a colocação de H. P. Lovecraft (2007, p. 13): “A emoção mais antiga e mais forte da humanidade é o medo, e o tipo de medo mais antigo e mais poderoso é o medo do desconhecido". Este fato permite compreender a origem 
$\begin{array}{llllllll}\mathbf{R} & \mathbf{E} & \mathbf{V} & \mathbf{I} & \mathbf{S} & \mathbf{T} & \mathbf{A} & \text { Dossiê - N. } 27-2014.1-\text { Alexander Meireles da Silva }\end{array}$

e função do medo ocupado pelas doenças e epidemias no imaginário da humanidade, o mesmo espaço ocupado na literatura gótica de temas medievais e folclóricos por diferentes criaturas sobrenaturais. Afinal de contas, semelhante a um demônio que se apodera de uma pessoa, os vírus e bactérias não podem ser vistos, mas também desfiguram os corpos possuídos. No Brasil da República Velha, todavia, dada sua insalubre condição de vida e o contato próximo com a doença, o povo se torna o alvo do medo das elites. Exemplo dessa ligação feita pelo discurso dominante está no conto "Palavras de um stegomya" (1925), da coletânea A bico de pena, de Coelho Neto, cuja narrativa amparada na tradição da fábula traz uma conversa entre um pernilongo e um narrador humano, em que o primeiro busca provar que são os cidadãos pobres da cidade os responsáveis pela transmissão da varíola devido à má qualidade do sangue que alimenta os insetos.

De volta a "A peste", Luciano Torres adentra o espaço topofóbico do hospital para visitar o jovem estudante Francisco, mas o que ele encontra é o próprio horror encarnado:

Eu tinha diante de mim um monstro. As faces inchadas, vermelhas e em pus, os lábios lívidos, como para arrebentar a sânie. Os olhos desaparecidos meio afundados em lama amarela, já sem pestanas e com as sobrancelhas comidas, as orelhas enormes. Era como se aquela face fosse queimada por dentro e estalasse em empolas e em apostemas a epiderme. Quis recuar, quis aproximar-se (RIO, 1981, p. 67).

Ao ser enxergado como um monstro, o jovem variloso transcende a categoria do humano para se tornar um ser intersticial, indo ao encontro das colocações de Noël Carroll sobre as fontes do horror artístico: "o que horroriza é o que fica fora das categorias sociais e é forçosamente desconhecido" (1999, p. 54). A Luciano Torres, nada mais resta senão evadir do hospital, mas o lugar não mais o abandonará e ao final do conto o narrador informa o leitor de que Luciano Torres também está com varíola. Chama a atenção, ao fim de sua narrativa, o fato de que João do Rio não responsabiliza os pobres ou negros, ou outras minorias como os responsáveis pela varíola, mas seu conto, no qual jovens morrem de forma horrenda, reforça a urgência das medidas sanitárias tomadas pelas autoridades para a eliminação da doença na cidade do Rio, mesmo que para isso os pobres fossem tratados como a própria doença.

Tão mortal quanto a varíola, a febre amarela desembarcou no Brasil junto com os navios negreiros, encontrando aqui um espaço propício para a sua propagação, devido ao grande número de insetos, dentre eles, o mosquito Aedes aegypti, transmissor da doença. A propagação da febre amarela em espaços próximos a matas e florestas estabeleceu um vínculo da doença com o não urbano, promovendo uma visão do mundo rural como o lócus do atraso e do medo. Como exemplo desta retratação, "O mosquito" (1927), de Coelho Neto, se 


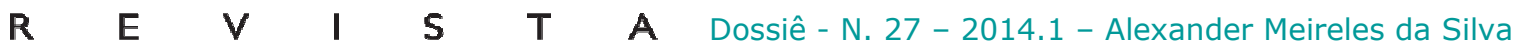

constitui em exercício sobre o medo como fonte do sublime, nos termos burkeanos. Essa leitura se inicia na abertura do conto, em que o narrador descreve o medo provocado pelo oceano quando ele estava em alto mar na Europa e viu seu navio ameaçado por uma onda gigante: "Foi um segundo trágico no qual me considerei perdido, com a catastrophe imminente [...]. Horrível, mas rápido - verdadeiro mergulho na morte" (COELHO NETO, 1927, p. 137). Essa descrição vai ao encontro das considerações de Edmund Burke sobre o oceano: "O oceano é objeto de um grande terror. De fato, o terror é, em todo e qualquer caso, de modo mais evidente ou implícito, o principio primordial do sublime" (BURKE, 1993, p. 66). Mas, ao ser perguntado pelo amigo aonde mais veio a encontrar outra situação em que ficou impotente de medo, o narrador responde: "Foi no sertão. Viajava eu, nesse tempo, por conta da casa Malveiro \& Simas e, apesar de avisado de que na cidade para onde me dirigia, grassava a febre amarella, ansioso, como estava, [...] toquei, contrariando o camarada" (COELHO NETO, 1927, p. 138). Semelhante ao viajante inglês, em "O hospede de Drácula" (1914), de Bram Stoker, que despreza os conselhos dos locais sobre a maldição de vampiros que cerca a floresta do leste europeu que ele desejava conhecer, o narrador de Coelho Neto não leva em conta as advertências do companheiro de viagem de que na cidade para onde ele se dirigia os mortos já estavam sendo enterrados "à beira das estradas, por não haver mais lugar no cemitério" (COELHO NETO, 1927, p. 139). Ao se hospedar no local, todavia, ele descobre tardiamente que está cercado pelo mosquito transmissor da febre amarela: "Um arripio relampejou-me ao longo da espinha. A voz enfesante do insecto, que me perseguia, teimoso, soou-me como aviso de morte" (COELHO NETO, 1927, p. 139). Decidido a dormir, o viajante percebe que a noite seria marcada pelo medo:

Estendi-me para dormir e ia adormecendo quando ouvi zumbir, não o zumbido comum do mosquito, mas um som lúgubre que atroava medonhamente o silêncio, um som de morte e que, por vezes, parecia esgargalhar zombeteiro. [...] Allucinação ou lá o que fosse, a verdade é que, de repente, o cubículo encheu-se de um futum de carniça, fétido horrível de podridão. [...] O mosquito zumbia sempre, mas onde? onde? Por mais que eu o procurasse não conseguia descobri-lo. Quem póde vêr a morte? E aquillo outra coisa não era senão um serviçal da Peste que, com seu enxame, toma d'assalto a cidade (COELHO NETO, 1927, p. 141-142).

A menção da personagem, de que pode estar sofrendo de alucinações em decorrência de seu medo, mostra a corporificação do mosquito como fonte do sublime. Esse comportamento corrobora a descrição de Edmund Burke sobre esse sentimento:

Nenhuma paixão despoja tão completamente o espírito de todas as suas faculdades de agir e de raciocinar quanto o medo. [...] Portanto, tudo que é terrível à visão é igualmente sublime, quer essa causa de terror seja dotada 


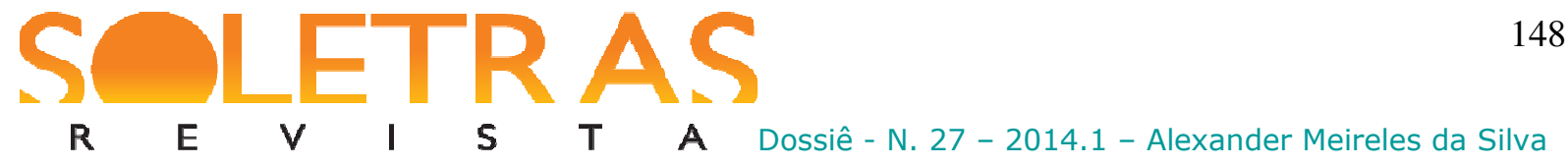

de grandes dimensões ou não, [...]. Existem muitos animais que, não sendo de grande porte, são contudo capazes de suscitar idéias do sublime, porque são visto como objetos de terror (BURKE, 1993, p. 65-66).

Ao amanhecer, o narrador de "O mosquito" foge da cidade morta, mas o terror de ter passado a noite cercado pela morte o marca de forma permanente: "Mas ainda hoje - e quantos annos lá vão - se ouço zumbir um mosquito estremeço, lembrando-me daquela noite no rancho" (COELHO NETO, 1927, p. 142). É interessante mencionar que essa associação feita pelo viajante entre o sertão, doença e morte também marca a representação do homem do campo em "Velha praga" (1918), de Monteiro Lobato, conto este que, ao lado de outras obras do escritor paulista, foi marcado pelas crenças eugenistas de Lobato de que o sertão e seus habitantes eram um entrave para o progresso da nação brasileira. Ao explicar a praga que assolava as matas do sertão com queimadas e destruição, ele diz: "Este funesto parasita da terra é um CABOCLO” (LOBATO, 1985, p. 141).

Além da febre amarela, o sertão também é o espaço de manifestação da lepra, doença bíblica que marca presença na literatura brasileira em contos regionalistas como, dentre outros, "Camunhengue" (1920), de Valdomiro Silveira, em que um pai de família descobre a doença e a gradual segregação social decorrente da doença e "Pelo caiapó velho" (1917), de Hugo de Carvalho Ramos, trazendo a visitação de um vaqueiro a uma casa abandonada habitada por uma leprosa no meio do sertão. Em "Niobe" (1927), Coelho Neto parte da mitológica figura feminina que dá título ao conto cujos filhos e filhas foram mortos em represália à falta de respeito da mortal pelos deuses, para apresentar a narrativa de uma mãe que, gradativamente, perde seus filhos para a lepra. A utilização por parte de Coelho Neto desta personagem mítica se dá pelo fato de que a lepra contraída pelas crianças equivalia a uma sentença de morte visto que os leprosos se tornavam mortos-vivos sociais, algo oficializado na Idade Média através da cerimônia Separatio Leprosarium, desenvolvida ao longo dos séculos doze e treze na Europa medieval, em que um indivíduo tinha sua cabeça coberta por um véu negro e era conduzido por um padre e os demais membros de sua comunidade até um cemitério. Neste local, a pessoa era colocada em uma cova aberta e o clérigo derramava terra sobre sua cabeça ao mesmo tempo em que eram proferidas as palavras "Sic mortuus mundo, vivus iternum Deo", anunciando que, a partir daquele momento, ele estava "morto para o mundo, renascido em Deus" (SILVA, 2013, p. 128). Não à toa, quando o filho mais velho é levado ao campo para evitar a contaminação dos demais irmãos e irmãs o leitor é informado que, "Com a partida do menino a casa cerrou-se em melancolia como se nella houvesse morrido alguém" (COELHO NETO, 1927, p. 32). Neste meio tempo, a mulher 
R E V I $\quad$ S $\quad$ T $\quad$ A Dossiê - N. 27-2014.1-Alexander Meireles da Silva

e o marido, buscando aplicar a lógica racionalista à questão, se questionam como a lepra teria entrado em sua casa: "Como teria ele adquirido aquella horrível doença? [...] Uma noite, marido e mulher, conversando à varanda, recorreram a toda a parentela, revolvendo mortos a ver se, entre eles encontravam vestígios da moléstia" (COELHO NETO, 1927, p. 32). Para o desespero da mãe, no entanto, o segundo filho também começa a manifestar a moléstia: "A desgraçada não poude dominar a revolta do coração torturado contra tamanha fatalidade. Era um castigo do céu, mas porque? Dois filhos, dois!" (COELHO NETO, 1927, p. 33). O questionamento sobre a possível ligação da desgraça que se abate sobre as crianças a um castigo estabelece o dialogo do conto com a temática gótica dos "Pecados do pai", exemplificada em $O$ morro dos ventos uivantes (1847), de Emily Brontë, através dos sofrimentos sentidos por uma geração em resposta às ações da anterior e que representavam a ameaça da deterioração social dentro do universo familiar. Como ressalta Fred Botting, "a casa e a família eram vistos como o último refúgio contra a sensação de perda e as forças ameaçadoras as relações sociais (BOTTING, 1996, p. 128) (Tradução nossa). No caso de "Niobe", a suspeita recai sobre os negros: "Atribuia aquillo a feitiço, a vingança dos negros, mas porque? Que fizera ella? [...] E deu para investigar analysar as pessôas que lhe frequentavam a casa e espionar os escravos. Nada!" (COELHO NETO, 1927, p. 33). A derrocada final da mãe vem com a descoberta da jovem Alice, que herdou a doença dos irmãos. A constatação da moléstia é demais para a sanidade da mãe, que

de repente desatou a rir e a rir, estrebuchando em riso, abateu no divan. $\mathrm{E}$ ali ficou extática, a sorrir, d'olhos altos, fitos como a acompanhar, em despedida, a alma que se lhe fôra, deixando-a vasia, desmantellada, como um edifício que desaba em ruína (COELHO NETO, 1927, p. 36-37).

Semelhante a "Pelo caiapó velho", em que a leprosa lasciva é usada como símbolo de um sertão selvagem em meio ao Brasil que buscava se modernizar, trazendo a vinculação do conto com a tradição do Gótico Colonial (SILVA, 2013, p. 136), o contexto escravocrata de "Níobe" traz à mente o passado de pecados, sofrimentos e maldições do Brasil colonial que pode se refletir no presente na manifestação da lepra nas gerações seguintes, infundindo uma dimensão sobrenatural a esta moléstia deformante.

Escrevendo sobre a cidade, em "O bebê de tarlatana rosa" e "A peste", ou sobre o sertão, em “O mosquito" e "Niobe", respectivamente João do Rio e Coelho Neto abordaram o impacto das doenças infecciosas e as epidemias sobre o fantástico brasileiro, no momento em que o Brasil, almejando reconhecimento internacional para a ampliação de seu mercado exterior, renegou sua herança colonial e rural, demonizando pessoas, comportamentos e 
SOLETR

R E

regiões vinculadas à sífilis, à varíola, à febre amarela e à lepra. Assim como a contração da maldição do vampiro ou do lobisomem no Gótico inglês vitoriano, a representação literária da contaminação com estas moléstias ameaçou o status quo do discurso racionalista positivista de "Ordem e Progresso", colocando em xeque duas realidades da República Velha.

\section{Referências bibliográficas:}

AMIS, Kingsley. New maps of hell. London: New English Library, 1960.

AQUINO, MITTELMAN, Tania. A revolta da vacina: vacinando contra a varíola e contra o povo. Rio de Janeiro: Ciência Moderna, 2003.

AZEVEDO, A. O cortiço. Santiago: O Globo; Click Editora, 1997.

BOSI, Alfredo. História concisa da Literatura Brasileira. 47. ed. São Paulo: Cultores, 2006.

BOTTING, Fred. Gothic. London: Routledge, 1996. (The New Critical Idiom).

BURKE, Edmund. Uma investigação filosófica sobre a origem de nossas idéias do sublime e do belo. Trad. Enid Abreu Dobránszky. Campinas, SP: Papirus, 1993.

CAREY, John. Os intelectuais e as massas: orgulho e preconceito entre a intelligentsia literária, 1880-1939. Trad. Ronaldo Kyrmse. São Paulo: Ars Poética, 1993.

CARROLL, Noël. A filosofia do horror ou paradoxos do coração. Trad. Roberto Leal Ferreira. Campinas, SP: Papirus, 1999. (Coleção Campo Imagético).

CARVAlHO, J. M. de. Os bestializados: o Rio de Janeiro e a república que não foi. São Paulo: Companhia das Letras, 1987.

CAUSO, Roberto de Souza. Ficção científica, fantasia e horror no Brasil: 1875-1950. Belo Horizonte: Editora UFMG, 2003.

CHALHOUB, S. Cidade febril: cortiços e epidemias na corte imperial. São Paulo: Companhia das Letras, 1996.

COELHO NETO. O mosquito. In: COELHO NETO. Contos da vida e da morte. Porto: Livraria Chardron, 1926, p. 137-142.

COELHO NETO. Niobe. In: COELHO NETO. Contos da vida e da morte. Porto: Livraria Chardron, 1927, p. 31-38.

COHEN, Jeffrey Jerome. A cultura dos monstros: sete teses. In: SILVA, Tomaz Tadeu da. Pedagogia dos monstros: os perigos e os prazeres da confusão das fronteiras. Belo Horizonte: Autêntica, 2000, p. 23-61. 


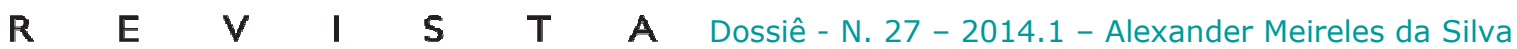

FARRELL, Jeanette. A assustadora história das epidemias: pestes e epidemias. Trad. Mauro Silva. São Paulo: Ediouro, 2002.

FERNANDES, Tânia Maria. Vacina antivariólica: ciência, técnica e o poder dos homens. Rio de Janeiro: Fiocruz, 1999.

LOBATO, Monteiro. Velha praga. In: LOBATO, Monteiro. Urupês. 31. ed. São Paulo: Brasiliense, 1985, p. 139-144.

LOVECRAFT, H. P. O horror sobrenatural em literatura. Trad. Celso M. Paciornik. São Paulo: Iluminuras, 2007.

NEEDELL, Jeffrey D. Belle époque tropical: sociedade e cultura de elite no Rio de Janeiro da virada do século. Trad. Celso Nogueira. São Paulo: Companhia das Letras, 1993.

RAMOS, Hugo de Carvalho. Pelo caiapó velho. In: DENÓFRIO, Darcy França, SILVA, Vera Maria Tietzmann (Orgs.). Antologia do conto goiano I: dos anos dez ao sessenta. Goiânia: CEGRAF; UFG, 1992, p. 55-59.

RICHARDS, Jeffrey. Sexo, desvio e danação: as minorias na idade média. Trad. Marco Antônio Esteves da Rocha e Renato Aguiar. Rio de Janeiro: Jorge Zahar, 1993.

RIO, João do. A peste. In: RODRIGUES, João Carlos (Org.). Histórias da gente alegre. Rio de Janeiro: Livraria José Olympio, 1981, p. 62-67.

. O bebê de tarlatana rosa. In: RODRIGUES, João Carlos (Org.). Histórias da gente alegre. Rio de Janeiro: Livraria José Olympio, 1981, p. 56-61.

Os livres acampamentos da miséria. In: RODRIGUES, João Carlos (Org.). Histórias da gente alegre. Rio de Janeiro: Livraria José Olympio, 1981, p. 79-84.

SAGA. Vol. 5. A vida nas cidades. São Paulo: Abril Cultural, 1981, p. 147-169.

SEVCENKO, Nicolau. A revolta da vacina. São Paulo: Scipione, 1993.

SEVCENKO, Nicolau. A revolta da vacina: mentes insanas em corpos rebeldes. São Paulo: Brasiliense, 1984. (Coleção Tudo é História).

SEVCENKO, Nicolau. Literatura como missão: tensões sociais e criação cultural na Primeira República. 3. ed. São Paulo: Brasiliense, 1989.

SILVA, Alexander Meireles da. Os mortos-vivos existem! O medo dos morféticos na literatura fantástica. In: GARCÍA, Flávio; FRANÇA, Júlio; PINTO, Marcello de Oliveira (Orgs.). As arquiteturas do medo e o insólito ficcional. Rio de Janeiro: Editora Caetés, 2013, p. 128-141.

THOMAS, Keith. Religião e o declínio da magia. Trad. Denise Bottmann e Tomás Rosa Bueno. São Paulo: Companhia das Letras, 1971. 


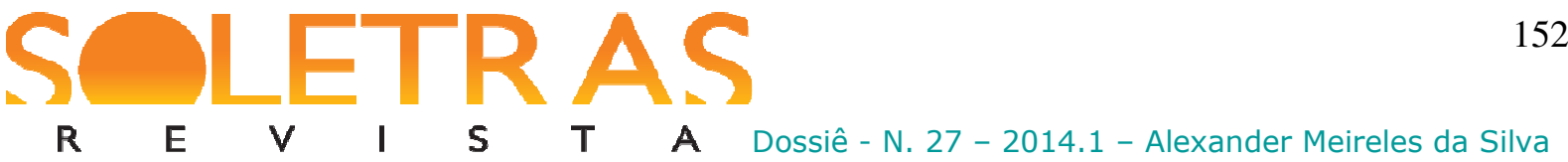

UJVARI, Stefan Cunha. A história e suas epidemias: a convivência do homem com os microorganismos. Rio de Janeiro: SENAC Rio, 2003.

ZANCHETTA, Maria Inês. Oswaldo Cruz: tudo pela saúde. Superinteressante, São Paulo, Editora Abril, nov. 1988, p. 49-53.

\title{
Under the domain of King Peste: the function of the diseases and outbreaks in Brazilian Gothic in the "República Velha"
}

\begin{abstract}
Though it has witnessed intense national conflicts such as the Canudos Rebellion, the Contestado War, the Vaccine Revolt and the Revolt of the Whip, the Old Republic (18891930) had in the plagues and outbreaks the fiercest enemies to be beaten in its project to the development of the country. Based on this statement and taking as critical support the monstruous concept by Noël Carroll and Jeffrey Jerome Cohen as well as H. P. Lovecraft's and Edmund Burke's ideas on the function of fear in fantastic literature, this article aims to demonstrating how syphilis, yellow fever, variole, bubonic plague and leprosy had a striking influence in the manifestation of literary narratives in Brazil whose structure and themes share similar elements with nineteenth-century Gothic Literature published in the United Kingdom and in the United States. Among other short stories by writers such as Valdomiro Silveira, Hugo de Carvalho Ramos and Monteiro Lobato, the analysis of "O bebê de tarlatana rosa" and "A peste", both written by João do Rio and "O mosquito" and "Niobe", written by Coelho Neto demonstrate that plagues and outbreaks were used by Brazilian writers to express the elite ideological view on social groups and geographical regions within the prevailing modern discourse in the country.
\end{abstract}

Key words: Old Republic. Brazilian Gothic. Outbreak.

Recebido em: 14 de maio de 2014 .

Aprovado em: 27 de agosto de 2014. 